\title{
AIRPORT TYPOLOGY FOR LCC POLICY CHANGES: A EUROPEAN PERSPECTIVE
}

\author{
Antonín KAZDA (D), Marek TURIAK (D), Karol GÖTZ (D) \\ Air Transport Department, University of Zilina, Zilina, Slovakia
}

Received 5 February 2019; accepted 27 January 2020

\begin{abstract}
This paper proposes a new airport typology that might arise from the expansion of airports with dominant low cost carrier traffic. In the first part of the paper, the typologies and different airport categorizations are reviewed with examples of current taxonomies used by principal international organizations. However, none of the current airport taxonomies takes into account low cost (LCC) carriers and cannot be used to create an airport market strategy with LCC operation. The paper highlights the characteristic of LCC features, the differences between the LCC airlines, and the characteristics of secondary - low cost airports. Finally, the paper proposes a new taxonomy of airports with low cost operations based on the airport data analysis and expert panel elucidation. For identification of airports with a high share of low cost carriers, Eurocontrol 2013 data on airline types and movements were used. The novel classification of low cost airports enables management to design marketing strategies to respond to LCC dominance and its implications. The main contribution of this research is to provide a novel classification for low cost airports which is relatively new phenomenon comparing with the problems of full service carriers dominance at large airports.
\end{abstract}

Keywords: airport typology, low cost airport, low cost carriers, hub airport, regional airport, Instrument Flight Rules (IFR) movements, airport catchment area.

\section{Introduction}

Nature is characterized by great variety, such as the diversity of plant and animal species. Scientists have always endeavoured to bring order to this chaos. Carl von Linné (1707-1778) is known as the father of modern taxonomy (Hansen, 2011) and typological method. Later this method was used in all other fields of research (Huutoniemi et al., 2010). According to Kazda (1985), typological method aims to specify type as a concept and on the basis of the information obtained the scientist seeks to identify the types to help categorize the acquired knowledge.

Typology is defined by several dictionaries as "a study or systematic classification of types that have characteristics or traits in common" (American Heritage Dictionary of the English Language, 2016) or "a study of how things can be divided into different types" (Collins COBUILD, 2018).

There is no single airport taxonomy at present. Every country, region or organisation usually categorises airports according to their needs. The most popular variables for airport typology focus on five different aspects: size (number of passengers, volume of freight, range of air ser- vices), geographical position (i.e. proximity to the capital), role (intercontinental rather than local hub), ownership (private or public) and association with a specific network (ATG, Air Transport Group, 2002). Within the research we analysed the 229 largest European airports - those European airports that handle more than 500,000 passengers a year.

To find or identify a single airport typology that would serve each and every stakeholder, state or organisation is a challenging task. The challenge is so big, that we could even call it impossible. Each of these stakeholders use different approaches to classify airports, stemming from their unique needs, experience or even rules adopted. The most common metrics and indicators are based on airport size characterized by number of aircraft movements, number of passengers, air cargo amount and offer of air services, geographical position (i.e. distance from o the capital); type of operation (point to point or hub; domestic, international or intercontinental), ownership (private or public), and many others subject to aspects that are uniquely used within each organisation.

In spite of the rise of low cost carriers (LCC) traffic in the recent decades and the key role of LCC in airport

${ }^{*}$ Corresponding author. E-mail: kazda@fpedas.uniza.sk 
development and policy making, no airport classification with respect to LCC role and approach has been defined. This research proposes to fill this gap, recognizing the interconnectedness between airport size, LCC share, airport market strategies and implication for airport policy making, in particular in defining the airport approaches and market strategies.

With LCC becoming important in the European air transport market it is necessary to identify their different positions with respect to airports. This in turn impact airport strategic decisions, policy choices, negotiating positions but also can influence decisions of public authorities in regional development planning.

Categorising LCC and airport dynamics can be useful for understanding the relationship between airports and LCCs, and helping to shape airport policies and market strategies and negotiating approaches, in particular towards LCCs.

The research presented in this paper is based on detailed traffic analyses of more than 200 airports across Europe with a combined passenger traffic (both LCC and traditional carriers) of more than $0.5 \mathrm{M}$ a year and elucidation of panel of experts.

Our aim was to research the influence of the LCC on the airport typology; how different shares of LCC traffic expressed in low cost airport categories could be characterised and how this could influence the airport market strategy. The main goal of the work was to explore and understand the influence of LCC on the proposed airport typology; to tailor categories to express and describe aptly different groups of low cost airports, and to initiate a discussion on how the proposed typology may be used to steer the airport policy.

Section 1 presents the study's theoretical framework. Section 2 defines the study's research objectives and describes the research methodology. In the Section 3 the results of the research are delivered. In the Section 4 the results of the Low cost airport typology are discussed and interpreted.

\section{Theoretical framework}

There is no uniform, integrated and complete European airport classification at present. Airport classifications may include runway (RWY) physical characteristics; specifications such as Aerodrome Reference Codes (ICAO, 2013); flight rules and type of operation Visual Flight Rules (VFR/IFR; domestic/international; Schengen/non-Schengen etc.); and can distinguish between different airports or airport typologies used for different regulations according to airport size (number of passengers) or traffic volume (number of movements). With respect to the number of passengers handled there are three different classification typologies in the European Union.

In line with the Decision of the European Parliament and of the Council of 23 July 1996 on Community guidelines for the development of the trans-European transport network (OJ L 228, 9.9.1996, Annex II, section 6) there are three categories of airports defined (European Commission, 2005):

1. International connecting points - generally with an annual passenger volume of no less than 5000 000;

2. Community connecting points - generally with an annual passenger volume of between 1000000 and 4999 999, and

3. Regional connecting points and accessibility points - generally with an annual passenger volume of between 250000 and 999 999).

The Committee of the Regions, for its part, proposed five categories of European airports in its Outlook opinion of 2 July 2003 (CdR 393/2002 fin) on regional airport capacities (European Commission, 2005):

1. Major Hub airports - over 25 million passengers;

2. National airports -10 to 25 million passengers;

3. Other 1:15 airports of 5 to 10 million passengers;

4. Other 2:57 airports of 1 to 5 million passengers;

5. Other 3:67 airports of 200000 to 1 million passengers.

The European Commission issued guidelines on the financing of airports and start-up aid to airlines departing from regional airports 2005/C 312/01, considers that there is a broad overlap between these two classification schemes and for the purposes of these guidelines has defined the following four categories (European Commission, 2005):

A. Category A - "large community airports", - more than 10 mil. passengers/year;

B. Category B - "national airports", passengers between 5 and 10 mil.

C. Category C - "large regional airports", passengers between 1 and 5 mil.

D. Category D - "small regional airports", less than 1 mil. passengers.

Comparison of these different classifications side by side is presented in Figure 1.

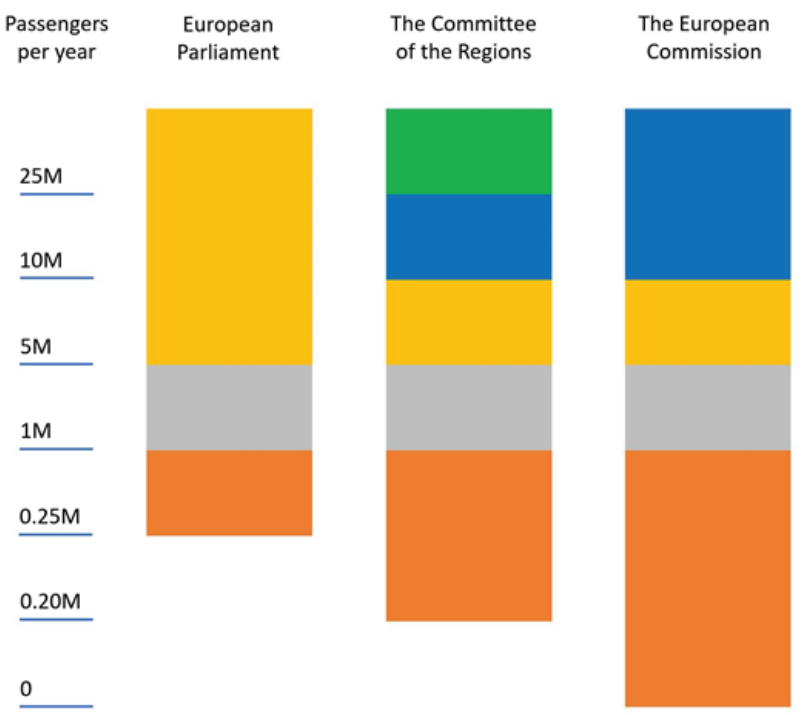

Figure 1. Three different airport typologies in the European Union 
Looking at the three various typologies used by the European Parliament, European Council, European Commission and Committee of the Regions it is clear that they are similar (see Figure 1). Still, they consider volumes of passengers as the only criterion for classification. From our point of view such a division has no benefits to an airport. These taxonomies fail to identify trends in the air transport, where the LCC are transforming regional airports into international gateways that offer direct pointto-point services, very often overlapping the boundaries of the given region, rather than connecting flights through a hub.

There are other similar classifications such as by ACI Europe, which takes passenger volumes in consideration (Airport Council International, 2013) or the ICAO classification with different passenger limits (ICAO, 2009). Eurocontrol, as an air traffic management organisation, collects and process data about flights. Therefore, they consider only airside operations at airports and are out of the scope of our research. The Boston Consulting Group distinguishes between four different types of airports: Primary International Hubs; Secondary Hubs; International "Origin and Destination" airports; and Regional Airports (Boston Consulting Group, 2004). We also researched other taxonomies within the study outside the Europe, i.e. the FAA's National Plan of Integrated Airport Systems (NPIAS) (FAA, 2009). According to our research, a classification that would differentiate various types of airports and categorise Low Cost Airports has not been formally formulated so far. Terms like "low cost airline, secondary airport and low cost terminal" are fairly established (Diaconu, 2012). However, they don't specify the type of relationship between the airport and LCC, which in turn would be useful for airport strategic decision making. Therefore, we have focussed on proposing an airport classification that would take into account the type of operations at the airport within the specific group "Low Cost Airports".

It is difficult to unambiguously define LCC and to accurately determine the number of carriers and airports served due to the spatial-commercial volatility of them. In 2015, Centre for Aviation (CAPA) and Official Airline Guide (OAG), both information companies in air transport, estimated that there were 31 LCC operating in Europe (CAPA, 2015), (Kerensky, 2007).

The differences between LCC and traditional operators has become less distinct in recent years. It is possible to distinguish five main types of LCC, each one referring to a specific economic model ranging from "pure" LCC (e.g. Southwest Airlines, Westjet, Ryanair, EasyJet); subsidiary companies (Eurowings, SmartWings); cut costs airline companies (Air Lingus; Brussels Airlines); transformed charter carriers (Thomsonfly, Norwegian); and state subsidised competing on price (Fly Dubai) (Francis et al., 2006).

Major drivers of the development of regional airports have been low-cost airlines. Generally, the low-cost airlines have accelerated the development of multi-airport systems in urban areas. The competition between the legacy and LCC is extending to their major factors of production, that is, the airports (de Neufville, 2007). The majority of LCC prefer to use secondary airports (Sedláčková \& Lokaj, 2017). Firstly, they take advantage of low charges. However, the more significant reason is that they prefer the smaller airports as the congestion there is low and therefore the delays on the ground as well as from air traffic control are non-existent (Warnock-Smith \& Potter, 2005). This ensures fast turn-around times, enabling an increase in the daily utilization and thus the productivity of LCC aircraft (Kazda \& Caves, 2015). For passengers less congested airports are associated also with less processing time spent on departure and arrival because terminal buildings are smaller. Car parking is usually cheaper at smaller airports. On the other hand, there is a different group of LCC that prefer primary airports in order to benefit from a different type of market and different passenger market segment (EasyJet, Vueling, Norwegian etc.). Low cost secondary airports in metropolitan areas compete with the traditional main ports. As the LCC expand along with these low cost airports, they reduce the market share of these legacy airports. The three most important airport requirements of LCCs are low airport charges, fast turnaround times and single-story airport terminals (Barrett, 2004a).

While introduction of low cost services can substantially boost the volume of operations at the airport, this does not necessarily mean that the airport becomes more viable from an economic point of view. LCC often have pre-conditions to their entry concerning aeronautical charges and often require additional support, for example in the form of marketing contributions financed from regional route development funds. This support can actually be higher at smaller airports than commercial revenue generated by passengers on the newly established low cost services (Sedláčková \& Novák, 2010).

High dependence on a small number of LCC is also seen as an issue by many airports, since (unless it is their main base) there are very low barriers for LCC to exit the market. The airports are therefore in a very vulnerable position. Many low cost airports try to diversify their activities and aim to become less dependent on LCC. Some attempt to attract more traditional services, others also focus on specialised services.

\section{Study objective and research methodology}

The research was conducted in two phases:

1. Identification of airports with a high share of LCC; data mining and data analysis.

2. Assessment of the impacts of LCC traffic on range of airports by Delphi Method (Kazda \& Caves, 2015), analysis of relationship between LCCs and airports, and definition of airport categories.

The first phase of the research we focused on obtaining robust and reliable traffic data on airport usage by different types of airlines included in the analysis, and ena- 
bling us to identify the exact share of any LCC airline at each airport. Through access to Eurocontrol's STATFOR Interactive Dashboard we were able to acquire average daily Instrument Flight Rules (IFR) movements data on a monthly basis. Eurocontrol collects and makes data available from January 2003, which gave us an opportunity to see the development of traffic at all airports in a span of 10 years $(2003-2013)^{1}$. Eurocontrol, what is crucial, also distinguishes in its statistics among different airline types and provides movement data for traditional, low cost, charter, business (i.e. general aviation operators) and cargo airlines (Eurocontrol, 2014). As a result, we were able to obtain exact traffic splits and precisely define LCC share at each individual airport. This data mining method was preferred to obtaining data directly from individual airports, also explored in a pilot phase, as it provided a wider data base and eliminated no-response risk factor.

In the first part of our research we used a statistical method with a selective finding sample selection (Turiak, 2015) and an application of historical method - data used for our research were created for a different purpose.

We were able to identify 229 of the largest European airports based on transported passengers in 2013. The data analysis showed all selected airports which have transported 500,000 passengers or more a year ${ }^{2}$.

The main goal of the second phase of research was to define specifications of particular group of LCC airports with respect to their economic and market position, practices of LCC in contracts negotiating, bargaining power of LCC and airports during negotiating, etc. Unfortunately those information are not publicly accessible and are mostly confident. Therefore, the Delphi Method was used for this phase of research.

Delphi research method is a popular, qualitative forecasting technique that has been widely applied to a wide variety of different problems. It has been extensively used in planning, policy analysis, and long-range forecasting, in both the public and private sectors (Gupta \& Clarke, 1996). It is a particularly appropriate method when there is no historical data or when "ethical or social dominate economic or technical ones" (Rowe et al.,1991). The Delphi Method captures a wide range of interrelated variables and multidimensional features common to most complex problems, both of which are necessary elements for detailed scientific analysis (Ray \& Sahu, 1990). It is also one

\footnotetext{
1 Newer data for year 2014 and 2015 are also available, however, for purposes of our research we have used data from the same calendar years in order for data to be compatible. Passenger data were not available mainly for 2014, therefore we chose year 2013 as the most suitable.

2 In some cases the number of transported passengers was lower, but not lower than 430000 passenger/year. This was done mainly to include airports with further potential of growth such as Brno - Tuřany or Maastricht Aachen into the analysis. Also only one Turkish airport is included due to unavailability of data at airports from the Asian part of Turkey as well as only a few selected airports from Russia and Ukraine.
}

of the multi-criteria decision-making methods (Petrović et al., 2019). Delphi Method is based on the fact that decisions from a structured group of individuals are more accurate than those from unstructured groups (Rowe \& Wright, 2001). Delphi's goal is not to elicit a single answer or to arrive at a consensus, but simply to obtain as many high quality responses and opinions as possible on a given issue from a panel of experts to enhance decision making (Gutierrez, 1989).

The key features of the Delphi Method are anonymity, repeated iterations of knowledge elicitation, resolution of differences, advocation of refined opinion and group feedback, all of which are key elements in effective group decision making (Rowe et al., 1991).

In our research a panel of experts from airlines, airports, state administration, academia, research and consultation companies from EU countries was set up. The panel consisted of sixty-two experts in total (see Figure 2). Standard two rounds of expert questioning were used. In the first round of expert consultation proposing of airport groups based on the data obtained in the first phase of the research and LCC airport classification were proposed. This was then submitted to the second round of expert consultation, providing a critical view on the proposed groups of airports, threshold settings between particular airport groups and proposed changes. As the thresholds to distinguish between different airport types are affected by multiple dependent variables, the Delphi Method was found as the most appropriate (Kalemba et al., 2017).

The analysis of the boundaries and conditions established for each group of airports included deletion of extremes of proposed thresholds and looking for the values preferred by most of the respondents. Based on comparison of proposed categories and panel of expert opinions the methodology to categorize airports was fine tuned.

\section{Results}

Conditions for airline operation at a particular airport, such as airport charges or different types of incentives, are generally not disclosed. They often differ significantly from the standard charges listed in the Aeronautical Information Publication (AIP) or on an airport web site. Similarly, neither airports nor LCCs publish any negotiation practices. However, these facts were crucial for airport groups determination and description of their specifications. The information on the LCC practices and conditions in entering a market and opening or closing a new route has been obtained by Delphi research method through the panel of experts from different airports, airlines, government bodies, academia, research and consultation companies on condition that neither their identity nor the organization name were disclosed. Based on expert panel interviewing, a proposal of LCC airport types was created in the second phase of the research with the aim to form groups of airports with similar characteristics with respect to LCC operations. The variables were airport traffic volume, the LCC share on a particular airport and practices of LCC 
Table 1. Airports by prevailing type of airlines in 2003 and 2013 (source: Turiak (2015) based on STATFOR data)

\begin{tabular}{|l|c|c|}
\hline \multicolumn{1}{|c|}{ Prevailing type of airlines } & 2003 Count & 2013 Count \\
\hline Traditional & 188 & 88 \\
\hline Low cost & 26 & 3 \\
\hline Charter & 7 & 2 \\
\hline Cargo & 1 & 1 \\
\hline Business (general aviation) & 5 & 0 \\
\hline Not in service & 2 & 2 \\
\hline
\end{tabular}

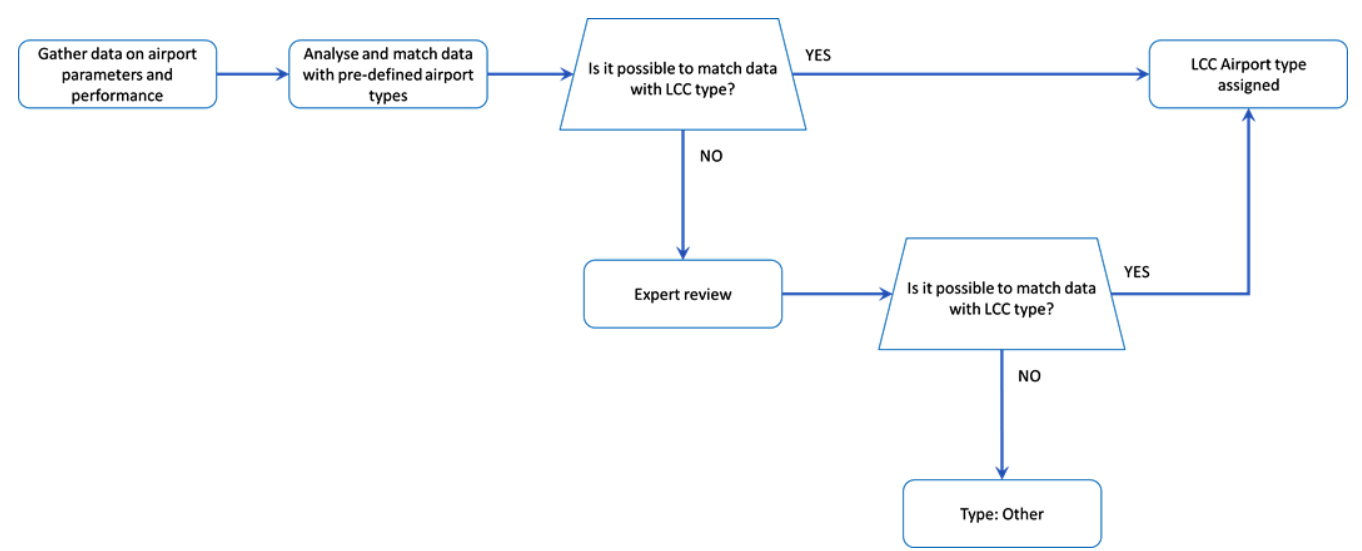

Figure 2. Flowchart of airport parameters performance indicator expert review, author Karol Gőtz

in contracts negotiating, bargaining power of LCC and airports during contract negotiating. In the second round of the Delphi Method elucidation the expert panel also reviewed LCC airport groups proposal.

Looking at the composition of airports by prevailing type of airline we can see in Table 1 that in 2003, out of 229 airports, there were 188 airports with prevailing traditional airlines in contrast to only 26 airports with dominant LCC operations. If we compare this with the 2013 data we can conclude that the situation has changed significantly. The number of airports with dominant operations of LCC has risen by $330 \%$ from 26 to 88 airports. On the other hand, airports with prevailing traditional operations were the ones that have transformed into low cost types as the number of airports with traditional prevailing operations has decreased by $28 \%$ from 188 to 135 airports.

In order to cover as many airports as possible we have also included in our analysis airports that have predominantly other types of traffic than low cost but at the same time the share of low cost airports was greater than $30 \%$. To include airport parameters significant to LCC operation in addition to the share of LCC traffic for each researched airport we also analysed the number of IFR movements, runway length data (as they have direct influence on aircraft type of operation) and airport slot coordination.

On top of "appropriate market" criterion the basic requirement for LCC operation is a suitable runway with a length of at least 2,000 metres and approved IFR pro- cedures. Due to LCC operational requirements and/or national CAA regulations some airlines also cannot use airports with the width of a runway less than $45 \mathrm{~m}^{3}$.

Another possible case is when an airport's parameters or performance indicators are not matching any of the four proposed airport types. In such a situation an expert review is needed to categorize the airport and assign type. In the case where it is not possible to assign type from LCC 1 to LCC 4, the airport is categorized as "other". The following flowchart is a visual representation of the process (Figure 2).

Based on those parameters (see Table 2 and Figure 3) the following four Low Cost Airport (LCA) types are proposed:

1. LCA 1 - Peripheral regional airports with LCC traffic

2. LCA 2 - Low cost secondary gateways of important economic nodes

3. LCA 3 - Large regional airports with significant share of LCCs

4. LCA 4 - Large primary airports with low share of LCCs.

3 Former military airports usually have a runway length of 2,000 meters, which is the ICAO Code Number 4 and a runway width of $30 \mathrm{~m}$. The runway width of 30 meters is sufficient in terms of the main gear wheel span for B737 or A320. However, at a runway width of 30 meters and an engine failure at a critical point during the take-off run, fast pilot reaction and experience is required to prevent an aircraft veer-off the runway. 
Table 2. Proposed low cost airport types (source: Turiak, 2015)

\begin{tabular}{|c|c|c|c|c|}
\hline Category & LCC traffic share (\%) & IFR movements/Y & RWY length (m) & Coordination \\
\hline LCA 1 & $15-100$ & $0-5,000$ & $1,800-3,000$ & No \\
\hline LCA 2 & $80-100$ & $5,000-30,000$ & $1,800-3,000$ & Irrelevant \\
\hline LCA 3 & $15-80$ & $>30,000$ & $1,800-3,000$ & Irrelevant \\
\hline LCA 4 & $0-15$ & $>100,000$ & $>3,000$ & Yes \\
\hline
\end{tabular}

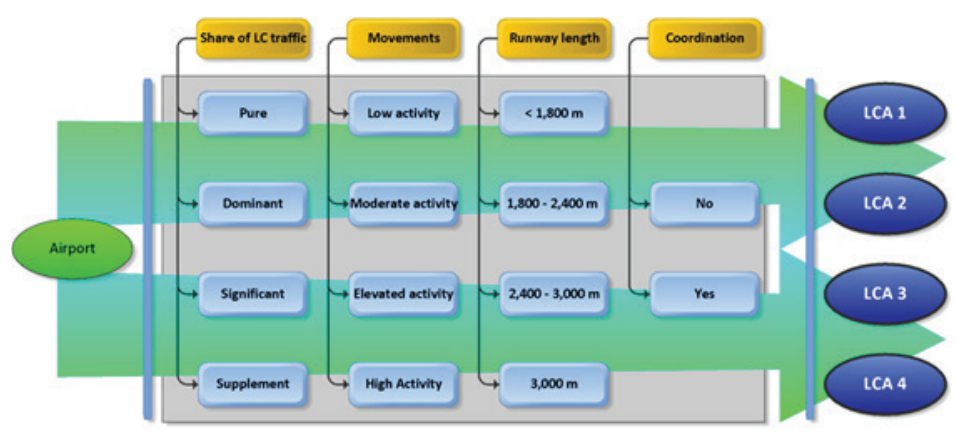

Figure 3. Flowchart of airport parameters performance indicator (source: Turiak, 2015)

The research conducted in 2015 gathered data on passengers, aircraft movements and on European airport characteristics for 229 airports, where the following split into four LCA categories has been identified (see Figure 3).

An analysis of data from the first and second phases of the research showed an interconnectedness between the low-cost airport category type, and airport strengths, weaknesses, opportunities and threats in relation with LCC operators. Based on the proposed typology we are able to classify all airports included in our analysis. The research also showed common features between airports of the same category and negotiation practices of LCC operators with airports of particular airport type. The position of an airport on the category grid had an implication for airport policy decisions.

\section{Discussion and interpretation of results - low cost airport typology}

Based on the previous data analysis and a panel of experts' interviewing we define four principal low cost airport types.

LCA 1 airports are in most cases regional airports in remote areas or areas with lower economic development. Due to their low overall activity they often offer a low number of connections, which can change very quickly in case there is no demand for such routes; airlines then try to change the destination mix or they leave the airport altogether. These are often former military airports; airports that were not used previously due to low demand in the past, or were closed during the "Great Recession". They could be owned and operated by local governments or Chambers of Commerce (France) (Aviation Strategy,
2001). Such airports, especially where they have high LCC traffic share but a low number of movements and low passenger volume, are the most vulnerable as they do not have strong bargaining powers. Airlines will not pay high fees at the airports where the prospect of profit is very low. The costs of such airport must be kept low under penalty of losing customer airlines. Actual or expected competition from other airports serving the same catchment area increases the potential for airlines to extract lower charges at competing airports. Examples of such airports are West Airport Knock, Reus, Doncaster-Sheffield or Brno Tuřany airport.

LCA 2 airports can be defined as secondary gateways of important economic nodes that are almost solely used by LCC. Their location ensures a steady influx of passengers and therefore their negotiating powers towards airlines are higher than those in LCA 1 . While at LCA 1 airports were able to negotiate discounted charges, for LCA 2 airports this is no longer possible and airlines are willing to pay standard fees; as they know that their position at the airport, which provides a stable source of income, can be taken over by a different airline that is willing to pay the standard charges. However, other possibly competing airports serving the same catchment area increase the potential for airlines to negotiate lower charges at competing airports, similarly as in the category LCA 1. Also, the number of connections and frequencies is higher. The share of LCC' traffic at the airport is also very high, ranging approximately from 80 to 100 percent. The scale of operations at some of these airports even requires airport slot coordination. Examples of such airports are Brussels Charleroi, Frankfurt Hahn, Glasgow Prestwick, Moss Airport Rygge, Liverpool or London Southend Airport. 


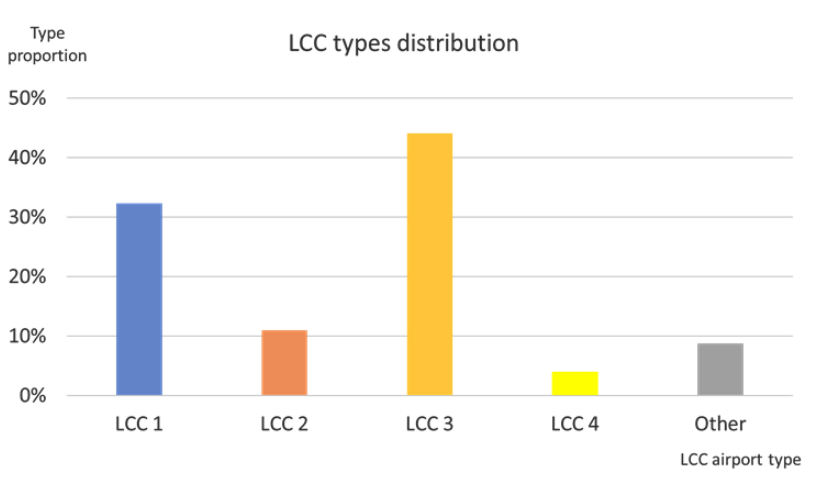

Figure 4. European low cost typology airport split

LCA 3 is the largest category (see Figure 4) as it includes secondary airports, large regional airports as well as primary hubs such as Schiphol, Stockholm or Madrid. This category might be further subdivided into those with spare capacity and without spare capacity (see below Southend Airport). The share of low cost traffic at these airports ranges from $15 \%$ at Marseille through to $66 \%$ at Gatwick airport to slightly over $80 \%$ at London Stansted. Different shares of LCC traffic at hub airports results mainly from the different LCC's business models. Whereas traditional LCC such as Ryanair or WizzAir are deliberately using secondary airports ${ }^{4}$, airlines such as easyJet or Norwegian are also operating at the primary airports (hub airports mentioned previously). Bargaining power of airlines differs as there are several models that need to be considered. Bargaining with a primary airport or sole airport in the region is almost impossible as it is the airline that wants to offer service from this particular airport. In case of large multiairport regions such as London with six airports there is a place for bargaining to a limited extent and time mainly because of a relatively new Southend Airport that is not utilizing its full capacity just yet. However, the Manston Airport, on the other side of the Thames estuary, failed to develop as a competitor as there is a limit to the extra travel time to airport, which makes lesser used airports less interesting to LCC airlines and their passengers. Airport slot coordination at these airports also varies, but in general the larger the scale of operations the more important the need for such measures is.

The last proposed category is LCA 4 which includes airports whose scale of operations is above 100,000 movements per year and the share of low cost traffic is less than $15 \%$. In fact, these are typically not low cost airports and should not be categorised under Low Cost Airport Typology. However, it was necessary to define all airports in the data sample and there are also LCC airlines operating from some of these airports. This category of airports might be subdivided into those which have slots available and those where slot purchase from an incumbent airline is the only mode of market entry by new airlines. Slots at

\footnotetext{
4 The policy of Ryanair changed last years and Ryanair uses also primary airports to address business passenger segment, as well.
}

hub airports are allocated according to longevity of the airline service at the airport under so-called grandfather rights. Start of LCC airlines operation from these airports might not be common. For example, Turkish Airlines bought a slot at London Heathrow in February 2015 for $\$ 22 \mathrm{~m}$ from SAS (Airportwatch, 2017). These are airports dominantly used by legacy carriers as their hubs. This category includes airports such as London Heathrow, Frankfurt, Brussels Zaventem, Charles de Gaulle Airport, Istanbul Ataturk, Zurich and Munich. All these airports have at least one secondary airport that accommodates most of the low cost traffic from the same market. LCC are more of a necessary evil for these airports as they could use the available airport slot for a service that would bring them higher revenues. Bargaining powers of LCCs are non-existent in this category.

\section{Conclusions}

The results of the research showed that similar airports face similar issues. Understanding the airport position with regards to the LCC market could help airports make strategic choices. At the same time, the LCC airport categorization could also be used by public authorities for regional development planning, enabling to define most appropriate, effective and efficient public policies.

From the 229 airports examined in the study, 74 or more than one third are the LCA1 type. It is the second largest group and represent airports which are many times in very difficult economic situations, and often requiring subventions. Low traffic levels hamper cost recovery, as many positions of airport costs are fixed (see Fernandes et al., 2016). Thus, whilst LCCs dictate prices (Zuidberg, 2017) these airports can either lower passenger or landing charges, introduce incentive schemes to attract LCC and increase the number of passengers or keep the traditional charging structure which results in passenger throughput decline. On the other hand LCA1 airports could have significant induced and catalytic impact on the surrounding region which outweighs the cost of regional airport subsidies (Kazda et al., 2017). The combination of LCC and low cost airports has made a huge impact on communities in excess of what the advocates of deregulation dreamed about two decades ago. Direct flights to regional airports by LCC are seen to be very beneficial to the communities served and are highly popular with the travelling public. The combination of LCC and low cost airports has caught high cost airlines and airports and the EU transport commission unawares (Barrett, 2004b). On the other hand, attempts to develop services at such airports by LCCs have been opposed at EU level by both legacy airlines and airports (Barret, 2017). It should be also emphasised that on today's low-cost airlines highly competitive market, the LCA 1 airports represents an important segment for the LCC growth and the number of suitable LCA1 airports is limited. As the situation in each of the airports is different, there is no single solution to solve their challenging situation. 
Airports of the LCA2 type (25 airports or $11 \%$ of the sample) are in present economic situation and strong market growth of LCCs in safe and stable position. Depending on the catchment area type their long-term policy goal should be to increase the traditional airlines share to balance the market.

Types of LCA1 and LCA3 represent the two largest groups in terms of LCC operations. However, it should be emphasized that the LCC position is diametrically different on both types of airports. On the LCA1 also the LCC position is not an easy one. Opening a new connection and increasing passenger numbers at small regional airports requires time and is high cost and high-risk related. It is therefore understandable that LCCs require airport or region participation to reduce risks (Kriel \& Walters, 2016). Conversely at LCC3 airports the LCCs benefit from mature, dense and stable markets but must face different problems; in particular airport capacity, slot coordination which have an impact on regularity of connections.

There are also airports which, according to specified parameters, do not fall to any of the LCC airport types (twenty airports or $9 \%$ - see Figure 4). They could be airports with a runway shorter than $1,800 \mathrm{~m}$ or a higher number of movements, typically training flights, so the share of LCC IFR movements is less than $10 \%$. To specify the airport LCC type, detailed analysis is needed in these cases.

Comparing with other airport typologies the LCC airport typology has no "exact boundaries" between particular types of airports. Because of the varied nature of airports in Europe it is sometimes possible for an airport to fall into two categories at the same time. In such a case an expert viewpoint is needed to assess which category suits the airport best. This shall be done based on the current and the forecast development of an airport. Also we are aware of the volatile nature of LCC and their executive decisions which are often unpredictable. They are able to withdraw from the particular airport in matter of weeks. Therefore an airport can change particular category very quickly. The market changes and changes of the economic situation could result in modifications of thresholds between airport groups in particular LCA1 and LCA2.

One of the principal benefits of the new airport typology for European Airports is that it allows them to assess their market position, bargaining power and define a policy for each airport. Based on trends connected to a certain airport an updated or even future category could be assigned, which gives an airport a robust argumentation tool for future negotiations with airlines. As an example, during our discussion with experts we found that there are airports which moved from the LCA 1 to LCA 2 but did not realized their shift in the market position and are still fearful to change their policy and increase their charges not to lose "their LCC" established at the airport. They were not aware of the fact that their airport position, negotiation and bargaining power has improved. There are also small airports which identified their position as LCA1 and by active marketing were able to increase the share of traditional airlines in their traffic split and stabilised their vulnerable position. Therefore, we would like to use several exercises of our methodology as encouraging material for those airports which still consider themselves the weaker negotiating partner.

The LCC types could differ on other markets like Asia or the North America. The research on this field could be interesting but it would require not only traffic data but also establishing a new panel of experts familiar with the different market situation.

\section{Funding}

The research was supported by the Cultural and Educational Grant Agency of the Ministry of Education, Science, Research and Sport of the Slovak Republic, project „New technologies and best practices in education in the Air Transport and Professional Pilots", project No. KEGA 011ŽU-4/201). This support is gratefully acknowledged.

\section{Disclosure statement}

Authors would like to declare that they do not have any competing financial, professional, or personal interests from other parties.

\section{References}

Airport Council International. (2013). Airport traffic report 2013. https://www.aci-europe.org/media-room-airport-traffic-report/member.html

Airportwatch. (2017). SAS raises $\$ 75$ million from Heathrow slot sale - virgin uses its slots as collateral. http://www.airportwatch.org.uk/2017/03/sas-raises-75-million-from-heathrowslot-sale-virgin-uses-its-slots-as-collateral/

American Heritage ${ }^{\oplus}$ Dictionary of the English Language (5th ed.). (2016). https://www.thefreedictionary.com/typology

ATG, Air Transport Group. (2002). Study on competition between airports and the application of state aid rules. http://ec.europa. eu/competition/sectors/transport/reports/airports_competition_2.pdf

Aviation strategy. (2001). Ryanair and its secondary airport policy. Aviation strategy, 41 (March), 83-94.

Barrett, S. (2004a). How do the demands for airport services differ between full-service carriers and low cost carriers? Journal of Air Transport Management, 10(1), 33-39. http://www.bcg. com/documents/file14335.pdf

Barrett, S. D. (2004b, February 20). Airports and communities in a deregulated market. Paper to Hamburg Aviation Conference (p. 120). Trinity College, Dublin. https://web.archive.org/ web/20110719034324/http://www.hamburg-aviation-conference.de/pdf/present2004/Session4_Panel_Barrett.pdf

Barret, S. (2017). Air transport liberalization: the case of Ireland (p. 88). In M. Finger \& K. Button (2017), Air transport liberalization. Critical Assesment, Elgar publishing.

CAPA. (2015). CAPA - Centre For Aviation. http://centreforaviation.com/data/airports/

Collins COBUILD Advanced English Dictionary. (2018). HarperCollins Publishers. https://www.collinsdictionary.com/dictionary/english/typology 
de Neufville, R. (2007). Low-cost airports for low-cost airlines: flexible design to manage the risks. Massachusetts Institute of Technology. Engineering Systems Division, 2007-03. http://hdl.handle.net/1721.1/102891

Diaconu, L. (2012). The evolution of the European Low-cost Airlines' business models. Ryanair Case Study. Elsevier Procedia - Social and Behavioral Sciences, 62 (24 October), 342346. https://doi.org/10.1016/j.sbspro.2012.09.054

Eurocontrol. (2014). Airports in European air network. http:// www.eurocontrol.int/sites/default/files/content/documents/ official-documents/trends-in-air-traffic/tat3-airports-in-european-air-network.pdf

European Commission. (2005). 2005/C 312/01 Communication from the commission - Community guidelines on financing of airports and start - up aid to airlines departing from regional airports (p. 4, para 12) https://eur-lex.europa.eu/legal-content/ EN/TXT/HTML/?uri=CELEX:52005XC1209(03)\&from=EN

FAA. (2009). Report to Congress. NPIAS 2011-2015. http:// www.faa.gov/airports/planning_capacity/npias/reports/media/2009/npias_2009_narrative.pdf

Fernandes, E., Pacheco, R. R., \& Braga, M. E. (2014). Brazilian airport economics from a geographical perspective. Journal of Transport Geography, 34, 71-77.

https://doi.org/10.1016/j.jtrangeo.2013.11.003

Francis, G., Humpreys, I., Ison, S., \& Aicken, M. (2006). Where next for low cost airlines? A spatial and temporal comparative study. Journal of Transport Geography, 14, 83-94 (2nd ed.). https://doi.org/10.1016/j.jtrangeo.2005.05.005

Gupta, U. G., \& Clarke, R. E. (1996). Theory and applications of the Delphi technique: A bibliography (1975-1994). Technological Forecasting and Social Change, 53(2), 185-211. https://doi.org/10.1016/S0040-1625(96)00094-7

Gutierrez, O. (1989). Experimental techniques for information requiremets analysis. Information and Management, 16, 3143. https://doi.org/10.1016/0378-7206(89)90025-6

Hansen, L. (ed.). (2007-2011). The linnaeus apostles - global science \& adventure ( 8 vols, 11 books). The IK Foundation \& Company.

Huutoniemi, K., Klein, J. T., Bruun, H., \& Hukkinen, J. (2010). Analyzing interdisciplinarity: Typology and indicators. Research Policy, 39(1), 79-88.

https://doi.org/10.1016/j.respol.2009.09.011

International Civil Aviation Organization (ICAO). (2013, July). Annex 14 Aerodromes, Vol. I. In Aerodrome Design and Operations (6th ed.), para 1.6.2 to 1.6.4. Montreal.

International Civil Aviation Organization STA/10-WP/7 (ICAO). (2009, 23-27 November). Review of the classification and definitions used for civil aviation. In Tenth session of the statistics division. Montréal. http://www.icao.int/Meetings/STA10/ Documents/Sta10_Wp007_en.pdf

Kalemba, N., Campa-Planas, F., Hernández-Lara, A-B., \& Sánchez-Rebull, M. V. (2017). Service quality and economic performance in the us airline business. Aviation, 21(3), 102-110. https://doi.org/10.3846/16487788.2017.1378266
Kazda, A. (1985). Obchodná prevádzková činnost', vybrané state (p. 22). Alfa Bratislava, výmer. č. 3430/84.

Kazda, A., \& Caves, R. (2015). Airport design and operation (3rd ed.) (pp. 25-27). Emerald Group Publishing Limited.

Kazda, A., Hromadka, M., \& Mrekaj, B. (2017). Small regional airports operation: unnecessary burdens or key to regional development. Transportation Research Procedia, 28, 59-68. https://doi.org/10.1016/j.trpro.2017.12.169

Kerensky, L. (2007). World's best low-cost carriers, 10082007. http://www.forbes.com/2007/08/09/travel-carriers-affordableforbeslife-cx_lk_0809biztravel.html

Kriel, E., \& Walters, J. (2016). Passenger choice attributes in choosing a secondary airport: A study of passenger attributes in using Lanseria International Airport. Journal of Transport and Supply Chain Management (JTSCM), 10(1), (2016). https://doi.org/10.4102/jtscm.v10i1.256

Petrović, M., Mlinarić, T. J., \& Šemanjski, I. (2019). Location planning approach for intermodal terminals in urban and suburban rail transport. Promet - Traffic \& Transportation, 31(1), 101-111. https://doi.org/10.7307/ptt.v31i1.3034

Ray, P., \& Sahu, S. (1990). Productivity management in India: A Delphi Study. International Journal of Operations and Production Management, 10, 25-51. https://doi.org/10.1108/01443579010005245

Rowe, G., \& Wright, G. (2001). Expert opinions in forecasting: role of the Delphi Technique. In J. S. Armstrong (Ed.), Principles of forecasting: a handook of researchers and practitioners. Springer Nature Switzerland AG. Part of Springer Nature. https://doi.org/10.1007/978-0-306-47630-3_7

Rowe, G., Wright, G., \& Bolger, F. (1991). Delphi: Re-evaluation of research and theory. Technological Forecasting and Social Change, 39, 235-251. https://doi.org/10.1016/0040-1625(91)90039-I

Sedláčková, A. N., \& Lokaj, P. (2017). Comparative analysis of U-fly and value alliance and global alliances. Paper presented at the Transportation Research Procedia, 28, 27-36. https://doi.org/10.1016/j.trpro.2017.12.165

Sedláčková, A. N., \& Novák, A. (2010). Simulation at the Bratislava airport after application of directive 2009/12/EC on airport charges. Transport and Telecommunication, 11(2), 50-59.

Turiak, M. (2015). Airport typology impact of low cost carriers operations ( $\mathrm{PhD}$ Thesis). University of Žilina.

Vogel, H.-A. (2016). Challenges of airport economics for financial management. Journal of Airport Management, 10(3), 416-435.

Warnock-Smith, D., \& Potter, A. (2005). An exploratory study into airport choice factors for European low-cost airlines. Journal of Air Transport Management, 1(11), 388-392. https://doi.org/10.1016/j.jairtraman.2005.05.003

Zuidberg, J. (2017). Exploring the determinants for airport profitability: Traffic characteristics, low-cost carriers, seasonality and cost efficiency. Transportation Research Part A: Policy and Practice, 101, 61-72. https://doi.org/10.1016/j.tra.2017.04.016 